\title{
Investigating European Genetic History through Computer Simulations
}

\author{
Mathias Currat Nuno M. Silva \\ Laboratory of Anthropology, Genetics and Peopling History (AGP), Department of Genetics and \\ Evolution - Anthropology Unit, University of Geneva, Geneva, Switzerland
}

\author{
Key Words \\ Computer simulation · Europe $\cdot$ Prehistory $\cdot$ Population \\ genetics · Ancient DNA
}

\begin{abstract}
Background/Aims: The genetic diversity of Europeans has been shaped by various evolutionary forces including their demographic history. Genetic data can thus be used to draw inferences on the population history of Europe using appropriate statistical methods such as computer simulation, which constitutes a powerful tool to study complex models. Methods: Here, we focus on spatially explicit simulation, a method which takes population movements over space and time into account. We present its main principles and then describe a series of studies using this approach that we consider as particularly significant in the context of European prehistory. Results and Conclusion: All simulation studies agree that ancient demographic events played a significant role in the establishment of the European gene pool; but while earlier works support a major genetic input from the Near East during the Neolithic transition, the most recent ones revalue positively the contribution of pre-Neolithic hunter-gatherers and suggest a possible impact of very ancient demographic events. This result of a substantial genetic continuity from pre-Neolithic times to the present chal-
\end{abstract}

lenges some recent studies analyzing ancient DNA. We discuss the possible reasons for this discrepancy and identify future lines of investigation in order to get a better understanding of European evolution.

(c) 2014 S. Karger AG, Basel

\section{Introduction}

The genetic diversity of human populations has been shaped by many forces during the course of their evolution, including past demographic fluctuation and migration. It is therefore possible to use genetic data from contemporary humans to attempt a reconstruction of the demographic history of ancestral populations using appropriate mathematical and statistical methods, as exemplified by more than half a century of research in human population genetics [see e.g. 1]. The simulation of evolutionary scenarios using computer programs is an approach that has greatly grown in popularity over the last decade due to the increase in computing power as well as to the development of more realistic models and sophisticated simulation frameworks $[2,3]$. Such scenarios consist of a combination of mathematical models including a series of parameters. The main principle underlying this model-based approach is to generate virtual genetic data

\section{KARGER}

E-Mail karger@karger.com

www.karger.com/hhe
(C) 2014 S. Karger AG, Basel

$0001-5652 / 14 / 0764-0142 \$ 39.50 / 0$
Mathias Currat

Laboratory of Anthropology, Genetics and Peopling History (AGP)

Department of Genetics and Evolution - Anthropology Unit, University of Geneva

12 rue Gustave-Revilliod, CH-1211 Geneva 4 (Switzerland)

E-Mail mathias.currat@ unige.ch 
for various alternative hypotheses (therefore various combinations of values assigned to the parameters), in order to evaluate which is the most (or the least) compatible with the observed genetic data. There are also statistical methods to formally evaluate the probability of alternative scenarios [4], such as the approximate Bayesian computation [5]. Computer simulation offers a theoretical framework that helps in the interpretation of empirical data and it can thus be seen as complementary to other descriptive or analytical approaches. One of its main advantages resides in the incorporation of various sources of information in the simulated models, such as genetics, archaeology and past environments.

Among all factors affecting genetic diversity, one is particularly difficult to take into account in mathematical models: the movements of populations over space and time. Indeed, human populations have always been highly mobile: they exchanged migrants, expanded to new areas and retracted to favorable climatic refuges during cold periods [6]. Because population dynamics played an important role in the evolution of our species, and thus in shaping its current genetic diversity, it is important to consider population dynamics in analyses, although this can lead to very complex models. Fortunately, spatially explicit computer simulation constitutes a very powerful tool to study how population movements in a geographic context, and especially the fluctuation of those movements over time, may affect the genetic diversity in conjunction with demographic variations.

The settlement history of Europe constitutes a topic for which spatially explicit simulations are particularly well-suited, because at least 3 large migratory and demographic events affected the genetic diversity of the entire continent. First of all, anatomically and behaviorally modern humans $(\mathrm{AMH})$ colonized Europe very rapidly from the East to the West within approximately 5,000 years between roughly 45,000 and 40,000 years ago [7], as revealed by the Aurignacian tool industry, which is usually attributed to AMH [8]. This initial expansion of the Homo sapiens coincided with the progressive disappearance of Neanderthals, another group of the genus Homo which occupied Western Europe for several hundred thousand years [9]. The most recent remains of Neanderthals have been found on the Iberian Peninsula and are dated to approximately 28,000 years ago [10]. Second, the peak of the last glacial period [the so-called last glacial maximum (LGM)] occurred between approximately 26,500 and 19,000 years ago [11]. During this period, the ice sheets were at their maximal extension, covering a large part of Northern and Central Europe, and this cer-

Simulation of European Prehistory tainly affected human distribution [6]. Although little is known about the dynamics of human populations during this time, it is quite probable that they retreated to the south, at least partly, following many species (plants and animals) $[12,13]$. Third, the European Neolithic transition occurred between 10,000 and 5,000 years ago, a profound cultural and economic change which took place all over the continent, with the progressive appearance of agriculture, herding and domestication as well as sedentary lifestyle and pottery [14]. This Neolithic transition spread from the Near East and Anatolia, where it had developed for several thousand years [15], to the Western and Northern fringes of Europe. The demographic and genetic consequences of this transition have been the subject of a long-standing, unsettled, debate among archaeologists, geneticists and paleodemographers. If the Neolithic transition marked the onset of a progressive and long demographic growth in Europe [see e.g. 16], it is not clear in which proportion it involved the arrival of early Neolithic farmers (FA) from the Near East and Anatolia, as opposed to an adoption of Neolithic techniques by local hunter-gatherers (HG). The first hypothesis is called 'demic diffusion' (DD) and implies that a large part of the current European gene pool entered Europe from the Near East and Anatolia during the Neolithic period [17]. The alternative hypothesis is called 'cultural diffusion' and implies that a large portion of the current gene pool was already present in Europe before the Neolithic process began [18]. Archaeology suggests that the Neolithic transition was achieved through a succession of cultural diffusion and migration phases in different regions [see e.g. 19, 20], while genetics yields contradicting results about the proportion of genetic 'replacement' (the proportion of the current gene pool derived from FA) during the Neolithic period. Estimations of this genetic replacement in Europe vary between 30 and $80 \%$ [see e.g. 21-23], the most recent estimates being slightly larger than $50 \%$ with a gradual decrease from the Southeast to the Northwest of the continent $[24,25]$. Inconsistencies between studies may be the outcome of a range of factors, including the large variety of methodological approaches taken and loci analyzed. It is good to recall at this point that gene trees are not population trees, and precisely for this reason, it is necessary either to take the genealogical stochasticity adequately into account in the analyses, or to consider multiple loci simultaneously when making demographic inferences. However, discrepant results certainly also highlight the complexity of the Neolithic process in Europe [26], such as different demographic histories for men and women $[27,28]$. So far, it has been difficult to 
disentangle the effects of those various factors and this calls for a general synthesis formally comparing the approaches for different kinds of loci.

One result which has often been reported is the occurrence of clinal genetic patterns over Europe. Most of those reported genetic gradients follow a Southeast to Northwest axis [SE-NW; see e.g. 29-33] but North-South [34] or East-West [35] gradients have also been observed. A direct causal relation between the Neolithic transition and the observation of SE-NW genetic clines has been shown in the work published by Menozzi et al. [30]. This seminal study summarized the combined information provided by 38 different alleles from 10 independent loci using principal component analysis (PCA). PCA is a general method for representing high-dimensional data, such as allele frequencies in populations, in fewer dimensions. When displayed on a geographic map, Menozzi et al.'s first principal component (PC1), summarizing $27 \%$ of the information, revealed a SE-NW gradient. Based on the similarity between this 'genetic' map and the map showing the dates at which the Neolithics appeared in various areas, Menozzi et al. [30] hypothesized that a dilution of alleles from FA during their expansion into Europe was the most probable explanation for this genetic cline. Since this influential study, the observation of genetic clines over Europe has been widely considered as a support to the DD model and consequently to a large Near Eastern and a low European pre-Neolithic genetic contribution to the current European diversity [see e.g. 17 but also 36,37$]$.

Here, we focus on the results obtained for the settlement of Europe using the spatially explicit simulation approach. First, we shortly describe this approach and then present a series of results obtained with it. We highlight one of the main outcomes which is, at odds with common belief, that clinal genetic patterns over Europe could have been generated not only by DD during the Neolithic period, but equally well by various more ancient demographic events. Finally, we discuss these results in the context of current research on the prehistory of Europe, in particular that involving ancient DNA (aDNA), underlining discrepancies and identifying future lines of research.

\section{Spatially Explicit Simulations}

Although 4 different programs have been used for the spatially explicit simulations performed in the 6 studies presented in the next section of this article $[28,38-42]$, their basic structure and principles are similar. Here, we thus intend to be as general as possible in describing the main principles of the 4 programs, but it is noteworthy that they differ by the presence or absence of certain parameters described below (and listed in table 1) as well as by variations in the demographic and genetic models assumed.

In a spatially explicit framework, the simulation of genetic data is achieved in a spatial context in which the movement of individuals (or genes) is a variable that directly influences the final output. Such a framework includes a geographic area represented by a numerical map in which the basic unit is a cell. Each cell is located in one specific position on a grid and may contain 1 or 2 demes (which represent populations; fig. 1a). The demes have specific characteristics that can be manipulated to best reflect the influence of the environment, thus providing a realistic context for the model to test. The movements of individuals (or genes) through space are regulated by a migration rate between demes belonging to neighboring cells (parameter $m$ ) and can be constrained by a friction value (parameter $f$ ) representing a topographic component of a given cell (e.g. a river, mountain, plain; fig. 1b, c). The maximum number of individuals that a given deme can reach is defined by its carrying capacity value (parameter $k$ ) and can be a function of the environmental information (e.g. vegetation type, topography) in order to represent to what extent natural resources in a given geographic location influence the density of a population. The speed at which the maximum density is logistically reached is defined by the growth rate (parameter $r$ ).

Assigning values to the 4 parameters described above and changing them in the course of time allows one to simulate the evolution of a particular population with the possibility to account for variations in topography (e.g. sea level changes allowing humans to cross or settle into new territories) and vegetation (e.g. from fertile plains to permafrost during ice age) that occurred in reality. Each simulation consists in computing the number of individuals (or genes) in each deme as well as the number of migrants between each pair of demes during a given number of generations (parameter $t$ ). When 2 demes are simulated in each cell, they represent 2 different populations with different characteristics in the same geographic location (e.g. HG and FA) and they can interact with each other. Different levels of admixture (the degree of assimilation of individuals from one population into the other; parameter $\gamma$ ) or competition (e.g. for the resources of the cell; parameter $\alpha$ ) can be simulated and will thus influence the demographic dynamics in each deme.

This combination of mathematical models and parameters allows one to simulate many different realistic scenarios, such as one population expanding from a source location to a wider geographic area that was formerly either empty (fig. 1b, c) or already occupied by another pre-established population with different characteristics. If the new invading population has a competitive advantage over the local one, then the latter may decrease demographically and eventually disappear. Additionally, a gene flow between populations may occur at various intensities in the form of assimilation of individuals from one population into the other. Population contraction towards a refuge area may also be simulated by decreasing the carrying capacity of demes, thus pushing individuals to emigrate. Geographic barriers to migration, such as a sea or a mountain, can also be easily taken into account using this approach.

Besides the spatially explicit information that this approach can cope with, the generation of genetic data is the second step of the 
Fig. 1. Spatially explicit simulation framework. a Schematic representation of the interactions between demes within and among cells. The growth rate $r$ and the carrying capacity $k$ define the demographic dynamics within a deme. The assimilation rate $\gamma$ and the competition rate $\alpha$ define interactions between demes within each cell. The migration rate $m$ defines interactions (the gene flow) between demes of the same populations (A or B) but located in neighboring cells. b, c Illustrations of a demographic expansion on a European map at 2 consecutive time points. Here, the expansion front is spreading from a location in Anatolia towards the West and North of Europe. There is only one deme (population) per cell. The shade of gray represents the densities within each deme (the darker, the larger the density). c The most favorable environment is shown by a black line, while white represents a geographic barrier (e.g. mountain or sea).

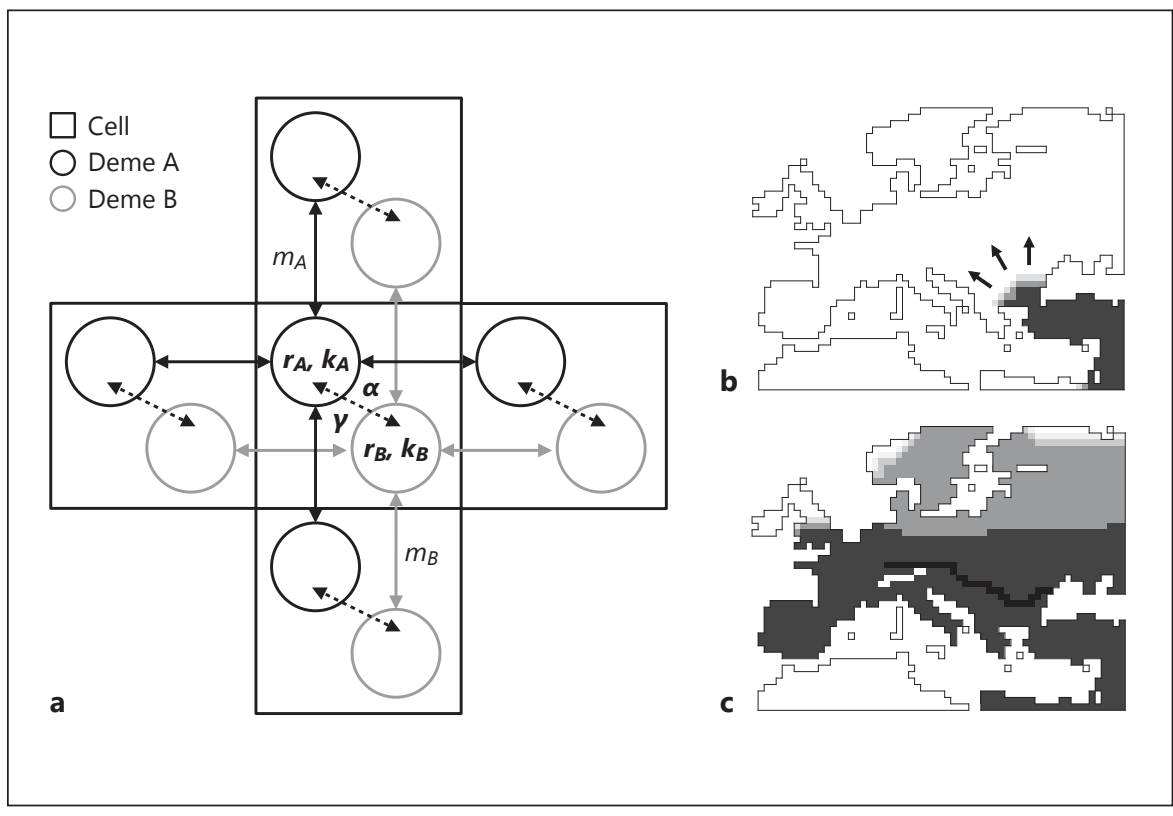

Table 1. The main characteristics of the 6 spatially explicit simulation studies described in the text and their main results

\begin{tabular}{|c|c|c|c|c|c|c|}
\hline & $\begin{array}{l}\text { Rendine et al. } \\
\text { [39] }\end{array}$ & $\begin{array}{l}\text { Barbujani et al. } \\
\text { [38] }\end{array}$ & $\begin{array}{l}\text { Currat and } \\
\text { Excoffier [40] }\end{array}$ & $\begin{array}{l}\text { François et al. } \\
\text { [41] }\end{array}$ & $\begin{array}{l}\text { Rasteiro et al. } \\
{[28]}\end{array}$ & $\begin{array}{l}\text { Arenas et al. } \\
\text { [42] }\end{array}$ \\
\hline Publication date & 1986 & 1995 & 2005 & 2010 & 2012 & 2013 \\
\hline HG expansion ${ }^{1}$ & no & no & yes & yes & yes & yes \\
\hline FA expansion ${ }^{3}$ & yes & yes & yes & yes & yes & yes \\
\hline Acculturation rate $\gamma^{4}$ & no & yes & yes & yes & yes & yes \\
\hline Allele frequency ${ }^{5}$ & yes & yes & yes & yes & yes & yes \\
\hline Molecular diversity ${ }^{6}$ & no & no & yes & yes & no & yes \\
\hline Sex-biased migration ${ }^{9}$ & no & no & no & no & yes & no \\
\hline Main results & $\begin{array}{l}\text { the Neolithic DD } \\
\text { model is compatible } \\
\text { with the observed } \\
\text { PC1 genetic cline }\end{array}$ & $\begin{array}{l}\text { the allele frequency } \\
\text { clines are } \\
\text { compatible with a } \\
\text { small or even absent } \\
\text { HG contribution }\end{array}$ & $\begin{array}{l}\text { the genetic structure } \\
\text { is also compatible } \\
\text { with a large HG } \\
\text { contribution; } \\
\text { the clines can be } \\
\text { generated by } \\
\text { different events }\end{array}$ & $\begin{array}{l}\text { a simple Neolithic } \\
\text { expansion from the } \\
\text { Near East is not } \\
\text { sufficient to explain } \\
\text { the } \mathrm{PC} 1 \text { genetic } \\
\text { gradient }\end{array}$ & $\begin{array}{l}\text { there are different } \\
\text { demographic } \\
\text { patterns for men } \\
\text { and women since } \\
\text { the Neolithic period } \\
\text { (i.e patrilocality); } \\
\text { the HG demography } \\
\text { also matters }\end{array}$ & $\begin{array}{l}\text { population } \\
\text { dynamics during } \\
\text { LGM played a } \\
\text { significant role } \\
\text { and a large HG } \\
\text { contribution is } \\
\text { supported }\end{array}$ \\
\hline
\end{tabular}

${ }^{1}$ The arrival of the Homo sapiens in Europe approx. 40,000 years ago. ${ }^{2}$ The migration to Southern refuges during the LGM approx. 22,000 years ago, followed by a recolonization towards the North. ${ }^{3}$ The Neolithic transition starting approx. 10,000 years ago. ${ }^{4}$ The variation in the acculturation rate $\gamma .{ }^{5}$ The generation of allele frequencies over Europe. ${ }^{6}$ The generation of molecular diversity (DNA, SNP, STR) in addition to allele frequencies. ${ }^{7}$ The influence of various environments on population demography. ${ }^{8}$ The competition for the resources between HG and FA. ${ }^{9}$ The separated migrations for men and women. ${ }^{10}$ SPLATCHE is available for free at www.splatche.com. 
simulation and it can be achieved through 2 different approaches: either a forward computation of allele frequencies in all demes at each generation [see e.g. 28, 38, 39] or a coalescent approach which reconstructs the genealogy of a series of sampled genes (or individuals) backward in time [see e.g. 40-42]. The second approach offers the advantage of being computationally much more efficient, allowing the study of more complex models in a reasonable amount of time. In both approaches, the virtual genetic diversity obtained at the end of a simulation is constrained by the demography of the simulated population and by a mutation model that depends on the kind of genetic data that is simulated (e.g. allele frequencies or molecular data). We redirect the reader to the original papers referenced above for more details about the exact procedures.

\section{Simulation of the European Genetic History}

Already in 1986, Rendine et al. [39] simulated the evolution of allele frequencies at several independent loci in European HG and FA populations, using a spatially explicit modeling framework. Their goal was to simulate the Neolithic DD and to evaluate if a SE-NW genetic cline similar to the one observed in Europe could be reproduced using PCA on simulated data. The virtual area was composed of 2 superimposed grids of demes (one layer representing $\mathrm{HG}$, the other FA). A gene flow between adjacent demes in the 4 cardinal directions within each grid was allowed (stepping-stone migrations) as well as between HG and FA demes located in the same position in each grid. The latter represented 'acculturation' of HG adopting farming techniques and was regulated by $\gamma$, which was kept constant for all simulations. A population expansion occurred only in the FA layer, while the HG layer was fully occupied during the whole simulation. The similarity between simulated and observed data led the authors to the conclusion that the reported SE-NW genetic cline was generated by the Neolithic DD.

Almost 10 years later, Barbujani et al. [38] published a more elaborate model comparing 5 different scenarios of the spread of Indo-European languages related to the diffusion of agriculture. In that study, the amount of HG contribution to the Neolithic farming community varied depending on the relative densities of FA and HG in each geographic cell, despite the fact that the acculturation rate $\gamma$ was kept constant. Another novelty compared to Rendine et al. [39] was the incorporation of environmental heterogeneity (3 types: plain, mountain and sea). This study showed that SE-NW genetic gradients were best explained by a population expansion from the Near East during the Neolithic period, due to a series of founder effects during the farmers' dispersal, either with a low contribution or a complete replacement of the local HG.

In 2005, Currat and Excoffier [40] extended this spatially explicit simulation approach with a series of more complex scenarios, notably involving: (i) explicit population expansions of HG in Europe corresponding to the arrival of $\mathrm{AMH}$; (ii) a competition between $\mathrm{HG}$ and FA which led to the progressive disappearance of $\mathrm{HG}$ after a period of local cohabitation with FA; (iii) the acculturation rate $\gamma$ varying between 0 (full genetic replacement of HG by FA) and 1 (random mating between HG and FA), and (iv) the generation of molecular information in addition to mere allele frequencies, in order to simulate mitochondrial and Y-chromosome data. Using the simulation program SPLATCHE [43], they showed that SENW allele frequency clines could have been generated equally well by the expansion of AMH in Europe around 40,000 years ago than by a latter expansion of Near-Eastern FA during the Neolithic transition. In other words, the observation of SE-NW genetic clines does not provide information about the amount of genetic replacement during the Neolithic transition. Both population expansions may have generated clines of allele frequencies along the axis of dispersion due to a phenomenon called 'allele surfing', which describes the rise in frequency of a neutral mutation in an expanding population [44, 45]. Moreover, Currat and Excoffier [40] showed that genes entering Europe from Anatolia and the Near East are expected to be very quickly diluted in the HG population in most situations, except if the local contribution of HG to the FA community is extremely low (a very small $\gamma)$. If a dilution was expected due to a progressive admixture among HG and FA communities [30], such a rapid one was surprising. This result is explained by the fact that HG alleles entered the FA population at the wave front of the expansion and thus had a larger probability to be amplified in the FA population due to the allele surfing phenomenon [40]. This result, combined with the low compatibility of the mitochondrial mismatch distributions observed in European populations and those generated under the Neolithic DD hypothesis model, led the authors to positively reevaluate the contribution of pre-Neolithic HG to the current European gene pool and consequently to challenge the proposal of a large genetic input from the Near East during Neolithic times.

In 2010, François et al. [41] used the same simulation framework as Currat, Excoffier and colleagues [SPLATCHE2, 46] with some parameter values adapted 
to the most recent findings. Instead of looking to average statistics obtained from independent loci, they focused on combined information from several loci using PCA. François et al. [41] plotted the 3 first principal components (PC1, PC2 and PC3) on a map of Europe, as was done by Menozzi et al. [30] with real data, in order to investigate the patterns obtained with simulated data. Unexpectedly, they found that a single expansion from the Near East during Neolithic times does not produce the SE-NW genetic gradient displayed by PC1 (i.e. the pattern observed in European data). In addition, this study revealed that in most cases where PC1 displays a gradient, its direction is not parallel to the axis of expansion but rather perpendicular to it. This can be explained, again, by the allele surfing phenomenon. Indeed, a neutral allele may increase in frequency along the axis of an expansion due to stochastic demographic effects, thus creating a cline. However, different alleles may have surfed at different places at the wave front, which also creates an axis of genetic differentiation perpendicular to the axis of expansion, because the different alleles may eventually become frequent, or even fixed, in different areas. The allele surfing phenomenon thus creates sectors of high allele frequency differentiation that align perpendicular to the direction of the expansion. The amount of genetic variation can eventually be larger perpendicularly to the main axis of dispersion than parallel to it, which leads to PC1 gradients perpendicular to the expansion [41]. Note that this effect was absent from Rendine et al.'s results [39] because they simulated alleles which were already frequent in $\mathrm{Eu}-$ rope at the onset of the Neolithic expansion, preventing the apparition of sectors. Indeed, to be detectable, the allele surfing effect must apply to alleles which are rare at the beginning of the expansion or which appear during it [45].

Among all parameter combinations tested by François et al. [41], the only model that generated SE-NW PC1 genetic gradients was the one simulating a postglacial expansion from Iberia starting around 20,000 years ago followed by a large HG genetic contribution $(>80 \%)$ during the Neolithic period. Those results thus showed that the interpretation of PCA maps in terms of past routes of migration is a complicated exercise because different processes may generate identical patterns. In addition, they also showed that clinal patterns over Europe could not be generated by a simple Neolithic expansion from the Near East and strongly suggested that the pre-Neolithic gene pool is likely to have substantially contributed to the make-up of the current European genetic diversity. Finally, their results also pointed to a possible impact of the population dynamics during the LGM on the European genetic structure.

Based on previous studies, Rasteiro et al. [28] developed their own forward, spatially explicit, simulation framework in order to investigate the effect of sex-biased migration during the Neolithic transition in Europe. Due to a greater demand in computing time, their simulations have certain limitations compared to those by François et al. [41], such as a lower resolution (smaller number of demes), the absence of competition between HG and FA and the non-use of molecular information. Nevertheless, they demonstrated that both different demographic histories for men and women since the Neolithic period and the demography of HG have influenced the European genetic diversity. They also suggested that patrilocality in farmer communities explain the current genetic patterns better than other alternative postmarital residence rules.

Little is known about what happened to human populations during the LGM, but it is very likely that they retreated to the South of the continent, at least partly, in order to follow food resources. Indeed many plants and animals moved to Southern refuges during the LGM, when ice sheets were covering most of Central and Northern Europe [13]. Arenas et al. [42] studied the genetic consequences of a potential retreat of humans towards the South of Europe during the LGM. They used the same simulation framework as François et al. [41] but added an important new process between the expansion of AMH and the Neolithic transition: a population contraction to the South of the continent was simulated between 25,000 and 21,000 years ago, followed by a postglacial re-expansion to the North starting around 18,000 years ago. Arenas et al. [47] investigated various scenarios of LGM contractions, either into the entire South of Europe or only into one single refuge area (either the Iberian Peninsula, Italy or the Balkans), and different kinds of migration patterns, either isotropic or anisotropic. Looking at the resulting PCA, they found that the most compatible PC1 was obtained when a postglacial expansion only from Iberia was simulated combined with a very small Neolithic replacement. This result is merely descriptive and based on a single type of analysis (i.e. PCA), but it tends to confirm the results previously obtained by François et al. [41]. It supports the view that the movements of people during the LGM have affected the current European genetic structure and that gene flow from the Near East during the Neolithic period was probably more limited than previously anticipated. 


\section{Simulation and aDNA}

Technical advances made during the last decade have enabled the sequencing of DNA from fossils dating from the Mesolithic and Neolithic periods mainly from Central and Northern Europe and the Iberian Peninsula [48-50]. There is a major discrepancy between the results obtained with spatially explicit simulations and those obtained using aDNA in the context of European evolution. Indeed, as described above (see also table 1), the most recent spatially explicit simulations point to a large contribution of pre-Neolithic populations to the current European gene pool. Contrarily, reports based on the analysis of aDNA suggest a genetic rupture between Mesolithic and Neolithic populations due to the arrival of people, possibly from the Near East [see e.g. 48, 51, 52], as well as due to a genetic discontinuity between Neolithic and contemporary populations [for different results, see also 53-55]. One explanation for this discrepancy may reside in the fact that aDNA has so far not been analyzed with spatially explicit simulations, which have only been using contemporary DNA. In particular, the test for a continuity/ discontinuity between pre- and post-Neolithic populations and contemporary populations is not based on spatially explicit simulations and mostly relies on the assumption of panmixia [one single population, e.g. 48, 50, 56]. It thus makes the strong assumption that, in the case of population continuity, the ancestral lineages of people living in a given area today have always been in the same area in the past. There are few exceptions to this assumption of panmixia which find that models incorporating ancient population structure (although very simply) are the ones that explain the data better $[27,49,57]$. Recently, Brandt et al. [58] have developed a new original test for population continuity, unfortunately it also fails to consider population structure. This assumption of (complete or almost complete) panmixia is questionable in view of the high mobility of humans as demonstrated by the series of simulations described below.

We simulated 1,000 times a population of constant size, divided into 2,500 demes $(50 \times 50$ subpopulations), exchanging migrants at rate $\mathrm{Nm}$ (where $N$ is the population density within a deme and $m$ is the migration rate between two adjacent demes), during 1,600 generations. Then we traced 30 lineages sampled at generation 1,600 (present) in the central deme back to different time points in the past and displayed the distribution of their ancestral lineages over the grid (fig. 2). Our results show that, at any point in the past, a very large majority (95\%) of the ancestral lineages are not found in the deme from

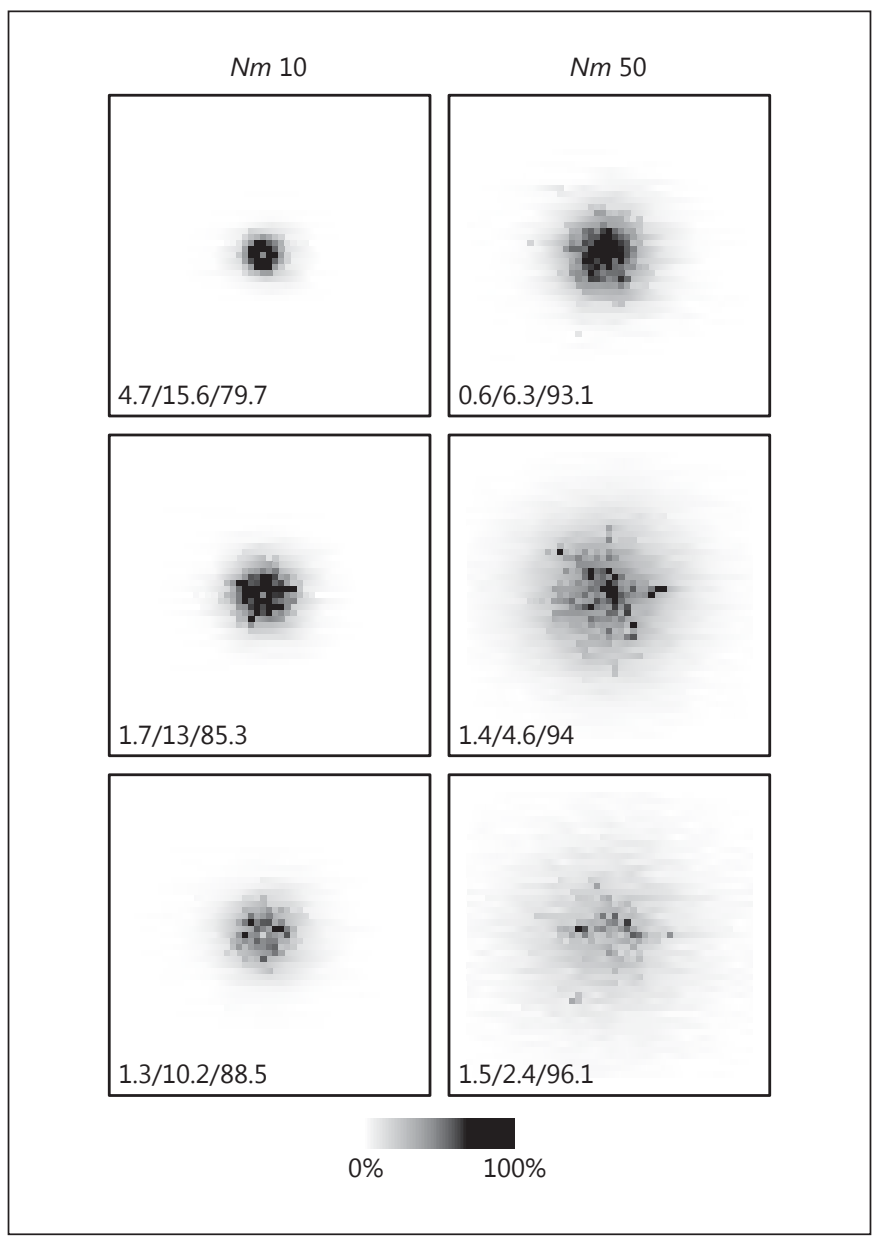

Fig. 2. Spatial distributions of ancestral lineages of modern samples at different time points in the past in a stationary population. The location of ancestral lineages of 30 genes which have been sampled at present (generation 1,600) in the central deme are shown in black. 1,000 simulations have been performed in each situation (using different time points and average gene flows $\mathrm{Nm}$ between the demes). The values within each square are the proportion of ancestral lineages in the central deme, that in the 8 demes around the central one and that in the rest of the area. In any case, less than $5 \%$ of all ancestral lineages are still in the sample's deme and less than $16 \%$ are in the direct neighboring demes. Top panels: generation 1,200 or approx. 10,000 years ago; middle panels: generation 800 or approx. 20,000 years ago; bottom panels: generation 0 or approx. 40,000 years ago.

where they were sampled, but are located in another deme, whatever the combination of demographic parameters simulated. Even around the Neolithic period, 400 generations before today (top panels in fig. 2), more than $95 \%$ of all lineages are outside the sample's deme and more than $79 \%$ are outside the area around the modern sampling's location (an area delimited by 8 demes 
around the central one). Our results also show that the spread of ancestral lineages increases with $\mathrm{Nm}$ and with time (fig. 2). This preliminary series of descriptive simulations demonstrates the necessity of taking both the spatial structure of populations and the movements of lineages into account in future analyses of population continuity.

One main difference between modern and ancient population samples is that the latter are often very heterogeneous both spatially and temporally. Given the scarcity of old fossil remains as well as the difficulty of extracting DNA from them, the so-called Mesolithic or Neolithic samples generally consist of individuals from different times but also different areas. For example, Bramanti et al. [48] used aDNA from HG bones with calibrated ages ranging from 13,400 to $2,250 \mathrm{BC}$ and geographic locations as distant as 2,900 km apart, while the ages of Neolithic samples range from 6,550 to 5,050 BC and the largest geographic distance is $1,000 \mathrm{~km}$ apart. Because ancient samples are heterogeneous in space and time and considered homogeneous in the analysis (i.e. the genes have been taken at different places at different times but are considered as one ancient population sample), this could potentially affect the calculation of statistics, such as the Fst statistics that is used to determine whether there is a genetic continuity between past and present populations. Currently, only temporal heterogeneity can be taken into account in the test for genetic continuity which is commonly applied to aDNA [59], but a new spatially explicit approach incorporating spatial heterogeneity would be highly valuable. Different levels of spatial and temporal heterogeneity within ancient population samples could eventually be processed with this kind of new tool in order to mimic real data such as in Haak et al. [52] and Der Sarkissian et al. [60].

\section{Discussion and Conclusion}

The spatially explicit simulation approach is complementary to other types of analyses and aims at providing both a theoretical framework for the interpretation of empirical data and an estimation tool. Its main strength is the integration of different sources of information (e.g. genetic, archaeological and environmental) into realistic models; this is particularly well-suited for the study of European evolution, a highly multidisciplinary topic. Moreover, this method constitutes a powerful tool to analyze spatial patterns of genetic diversity, which are quite common in Europe. It enables a formal testing of alterna-

Simulation of European Prehistory tive hypotheses by incorporating a population dynamic component (spatial and temporal), which likely played a significant role in establishing the current European genetic structure.

Although computer simulations may be used to study very complicated models that incorporate many parameters, more complexity does not necessarily equal more realism. For this reason, it is important to proceed in a step-by-step fashion when developing models of human evolution, thus studying in detail the influence of each new parameter on the results. As such, we believe that the series of studies presented in this article is an excellent example of this gradual increase in realism from the first model published in the 1980s up to the latest one published almost 30 years afterwards. Each study was able to build on the results and experience of the preceding one, with careful exploration of various aspects of the models. It should be noted that we intentionally chose to present those 6 papers which, in our view, constitute the most relevant studies of European evolution to date at the continental scale using genetic data and spatially explicit simulations. It was never our intention to present an exhaustive review of the modeling of populations' history in Europe, and there are other modeling studies focusing either on a smaller geographic area [61-63], on one single locus [64] or they are not spatially explicit $[65,66]$.

Summarizing the main results obtained with spatially explicit simulations of the European settlement history, all those studies agree that ancient demographic events played a significant role in the establishment of the European gene pool. There is a chronological trend towards support for the view that pre-Neolithic genetic diversity was not completely erased during the Neolithic period and that the contribution of local HG to the European gene pool was much more significant than previously anticipated. While the first work by Rendine et al. [39] supported the DD hypothesis model with a rather low HG assimilation, each new element added to the models in the following studies questioned the amount of genetic input from the Near East during the Neolithic transition. Although it remains difficult to estimate the proportion of genetic replacement during the Neolithic period, the latest spatially explicit simulation works clearly favor a major local genetic contribution across the continent over a large genetic replacement from the Near East [42]. Moreover, this local contribution is expected to increase with distance from the Near East, i.e. towards the Northwest of the continent, with all studies being concordant on this finding. The ex- 


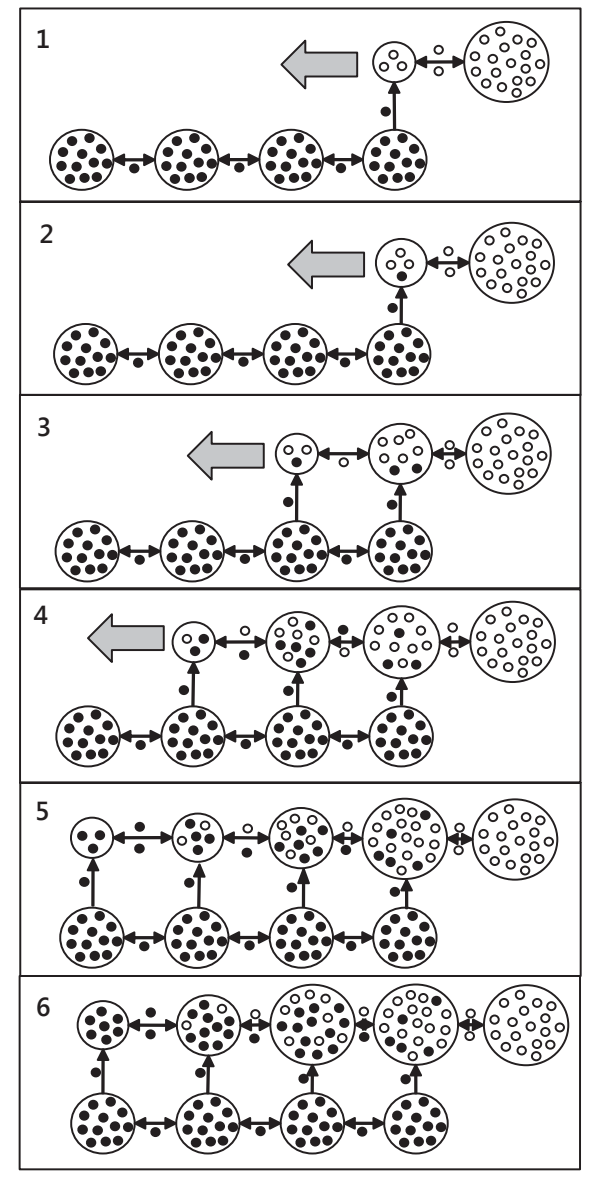

Fig. 3. Schematic representation of the spread of HG alleles during the Neolithic expansion. The 6 panels represent the advancing steps of the FA population from the East to the West in an area already occupied by HG. The large circles represent demes, their sizes reflect population densities. There was a rapid dilution of Near-Eastern FA alleles (white dots) during the Neolithic expansion due to a combined effect of a continuous gene flow of HG alleles (black dots) at the wave front and their rapid spread in the FA population because of the allele surfing phenomenon. This figure was modified from Petit and Excoffier [79].

tremely rapid dilution of genes of the first Near-Eastern FA into the European HG gene pool during their expansion is a major contribution of spatially explicit simulations to the question of European evolution. This rapid dilution can be explained by 2 processes: first, a continuous gene flow from the HG population at the wave front of the Neolithic expansion [as already noted by Rendine et al. 39] and second, a demographic amplification of HG alleles in the FA population due to the allele surfing phenomenon. What happened at the front of the Neolithic expansion wave was critical to the establishment of the final genetic structure (fig. 3). First, the pop- ulation density at the front was low, which means that the contribution of assimilated local HG alleles was proportionally high. Moreover, because of this low density, the genetic drift was high, and this increases the probability of dramatic frequency changes. Second, when the density at the front increased, so did the number of gene copies. Consequently, the probability that alleles present at the front reached higher frequencies in the final population was enhanced because individuals participating in the demographic growth had, on average, more children than at demographic equilibrium. Third, pioneers were recruited at the wave front and consequently had a higher probability to transmit their genes further away in the colonizing population.

Allele surfing seems to have played a major role in shaping the genetic structure of European populations, not only by contributing to the amplification of $\mathrm{HG}$ alleles in the FA population during the Neolithic transition, but also by creating genetic gradients over Europe. Spatially explicit simulations demonstrate that clinal genetic patterns may result from several separated demographic expansions: the arrival of $\mathrm{AMH}$, postglacial contractions and recolonization and the Neolithic transition, or more likely from a combination of them. The view that European genetic diversity has been shaped mainly by the Neolithic transition is thus challenged.

Allele surfing does not only mimic the effect of positive selection on neutral loci [67], but it can also affect alleles under selection [68]. It is thus very difficult to disentangle the relative contribution of demographic and selective factors in shaping the European genetic diversity. For instance, the diffusion of the lactase persistence trait (the ability to digest the milk sugar, lactose, in adulthood) is likely linked to the diffusion of domestication during the Neolithic transition and possibly under positive selection in dairying or Northern populations $[69,70]$. Spatially explicit simulation is a very promising tool to tackle the spreading pattern of lactase persistence in Europe [71] and more generally to study the effect of selection taking population dynamics into account; altough the simulations of selected genes require substantially more computational power than is needed for the study of neutral loci [72].

The inclusion of loci under selection in simulations will also make it possible to use the large HLA database, for which many population samples are available over all Europe $[73,74]$ and which has proven its potential when making evolutionary inferences [see e.g. 75]. Additional improvements which can be foreseen for future simulations of the European history include a better incorpora- 
tion of environmental and archaeological information, such as different vegetation types, elevation, topography, hydrography, long distance and coastal dispersal $[76,77]$.

Comparing ancient samples dating from the Mesolithic or Neolithic period with samples of contemporary Europeans often leads to the conclusion of a genetic discontinuity between past and present populations in the same area [see Deguilloux and Mendisco, 78], even if this abrupt genetic change remains largely unexplained. These results therefore challenge those obtained by spatially explicit simulations using modern DNA, which support the view that a large part of the current European gene pool traces back to pre-Neolithic people. A straightforward way to potentially reconcile spatially explicit results based on modern DNA with those of aDNA simulations performed with nonspatially explicit models may be to merge the 2 approaches (i.e. to perform spatially ex- plicit simulations with aDNA). We believe that considering the spatial dynamics of populations over time as well as the heterogeneity of ancient samples in the analyses of aDNA will certainly bring new insight on the evolution of Europeans.

\section{Acknowledgments}

We would like to warmly thank the organizers of the conference 'Genetic Diversity and the Origins of Europeans' held in Geneva in January 2013 as well as this special issue's editors G. Barbujani and A. Sanchez-Mazas for having invited us to write this article. We also acknowledge L. Excoffier, M. Arenas and A. Sanchez-Mazas for stimulating discussions on this topic, and E.S. Poloni and two anonymous reviewers for a careful reading of an early version of this paper. This work is financially supported by the Marie Curie initial training network BEAN and M.C. also received financial support from the Swiss NSF (grant No. 31003A-144180).

\section{References}

1 Cavalli-Sforza LL, Menozzi P, Piazza A: The 10 Finlayson C, Pacheco FG, Rodriguez-Vidal J, History and Geography of Human Genes. Princeton, Princeton University Press, 1994, pp 145-154.

- 2 Arenas M: Simulation of molecular data under diverse evolutionary scenarios. PLoS Comput Biol 2012;8:e1002495

- 3 Hoban S, Bertorelle G, Gaggiotti OE: Computer simulations: tools for population and evolutionary genetics. Nat Rev Genet 2011; 13:110-122.

-4 Csilléry K, Blum MG, Gaggiotti OE, François O: Approximate Bayesian Computation $(\mathrm{ABC})$ in practice. Trends Ecol Evol 2010;25: 410-418.

5 Beaumont MA, Zhang W, Balding DJ: Approximate Bayesian computation in population genetics. Genetics 2002;162:2025-2035.

-6 Verpoorte A: Limiting factors on early modern human dispersals: the human biogeography of late pleniglacial Europe. Quat Int 2009; 201:77-85.

7 Higham T, Compton T, Stringer C, Jacobi R, Shapiro B, Trinkaus E, Chandler B, Groning F, Collins C, Hillson S, O'Higgins P, Fitzgerald C, Fagan M: The earliest evidence for anatomically modern humans in northwestern Europe. Nature 2011;479:521-524.

8 Mellars P: Archeology and the dispersal of modern humans in Europe: deconstructing the 'Aurigniacian'. Evol Anthropol 2006;15:167-182.

-9 Banks WE, d'Errico F, Peterson AT, Kageyama M, Sima A, Sanchez-Goni MF: Neanderthal extinction by competitive exclusion. PLoS One 2012;3:e3972. et al: Late survival of Neanderthals at the southernmost extreme of Europe. Nature 2006;443:850-853.

11 Clark PU, Dyke AS, Shakun JD, Carlson AE, Clark J, Wohlfarth B, Mitrovica JX, Hostetler SW, McCabe AM: The last glacial maximum. Science 2009;325:710-714.

12 Banks WE, d'Errico F, Peterson AT, Vanhaeren M, Kageyama M, Sepulchre P, Ramstein G, Jost A, Lunt D: Human ecological niches and ranges during the LGM in Europe derived from an application of eco-cultural niche modeling. J Archaeol Sci 2008;35:481-491.

13 Hewitt GM: The genetic legacy of the Quaternary ice ages. Nature 2000;405:907-913.

14 Mazurié de Keroualin K: Genèse et diffusion de l'agriculture en europe: agriculteurs, chasseurs, pasteurs. Paris, Errance, 2003.

15 Ozdogan M: Archaeological evidence on the westward expansion of farming communities from eastern Anatolia to the Aegean and the Balkans. Curr Anthropol 2011;52:S415-S430.

16 Bocquet-Appel JP: When the world's population took off: the springboard of the Neolithic demographic transition. Science 2011;333: 560-561.

17 Ammerman A, Cavalli-Sforza LL: The Neolithic Transition and the Genetics of Populations in Europe. Princeton, Princeton University Press, 1984.

18 Zvelebil M, Zvelebil KV: Agricultural transition and Indo-European dispersals. Antiquity 1988;62:574-583.

19 Zvelebil M: The agricultural transition and the origins of Neolithic society in Europe. Documenta Praehistorica XXVIII 2001;Neolithic studies 8:1-26.
20 Bocquet-Appel JP, Naji S, Linden MV, Kozlowski JK: Detection of diffusion and contact zones of early farming in Europe from the space-time distribution of $14 \mathrm{C}$ dates. J Archaeol Sci 2009;36:807-820.

21 Richards M, Macaulay V, Hickey E, et al: Tracing European founder lineages in the Near Eastern mtDNA pool. Am J Hum Genet 2000;67:1251-1276.

22 Belle EM, Landry PA, Barbujani G: Origins and evolution of the Europeans' genome: evidence from multiple microsatellite loci. Proc Biol Sci 2006;273:1595-1602.

23 Balaresque P, Bowden GR, Adams SM, Leung HY, King TE, Rosser ZH, Goodwin J, Moisan JP, Richard C, Millward A, Demaine AG, Barbujani G, Previdere C, Wilson IJ, Tyler-Smith C, Jobling MA: A predominantly Neolithic origin for European paternal lineages. PLoS Biol 2010;8:e1000285.

24 Dupanloup I, Bertorelle G, Chikhi L, Barbujani G: Estimating the impact of prehistoric admixture on the genome of Europeans. Mol Biol Evol 2004;21:1361-1372.

25 Belle EM, Ramakrishnan U, Mountain JL, Barbujani G: Serial coalescent simulations suggest a weak genealogical relationship between Etruscans and modern Tuscans. Proc Natl Acad Sci USA 2006;103:8012-8017.

-26 Pinhasi R, Thomas MG, Hofreiter M, Currat $\mathrm{M}$, Burger J: The genetic history of Europeans. Trends Genet 2012;28:496-505.

27 Rasteiro R, Chikhi L: Female and male perspectives on the Neolithic transition in Europe: clues from ancient and modern genetic data. PLoS One 2013;8:e60944. 
28 Rasteiro R, Bouttier PA, Sousa VC, Chikhi L: Investigating sex-biased migration during the Neolithic transition in Europe, using an explicit spatial simulation framework. Proc Biol Sci 2012;279:2409-2416.

29 Barbujani G, Pilastro A: Genetic evidence on origin and dispersal of human populations speaking languages of the Nostratic macrofamily. Proc Natl Acad Sci USA 1993;90: 4670-4673.

30 Menozzi P, Piazza A, Cavalli-Sforza L: Synthetic maps of human gene frequencies in Europeans. Science 1978;201:786-792.

- 31 Chikhi L, Destro-Bisol G, Bertorelle G, Pascali V, Barbujani G: Clines of nuclear DNA markers suggest a largely Neolithic ancestry of the European gene pool. Proc Natl Acad Sci USA 1998;95:9053-9058.

- 32 Rosser ZH, Zerjal T, Hurles ME, et al: Y-chromosomal diversity in Europe is clinal and influenced primarily by geography, rather than by language. Am J Hum Genet 2000;67:15261543.

33 Sokal RR, Oden NL, Wilson C: Genetic evidence for the spread of agriculture in Europe by demic diffusion. Nature 1991;351:143-145.

- 34 Lao O, Lu TT, Nothnagel M, et al: Correlation between genetic and geographic structure in Europe. Curr Biol 2008;18:1241-1248.

35 Heath SC, Gut IG, Brennan P, et al: Investigation of the fine structure of European populations with applications to disease association studies. Eur J Hum Genet 2008;16:14131429.

-36 Barbujani G, Bertorelle G: Genetics and the population history of Europe. Proc Natl Acad Sci USA 2001;98:22-25.

37 Bollongino R, Nehlich O, Richards MP, Orschiedt J, Thomas MG, Sell C, Fajkosova Z, Powell A, Burger J: 2000 years of parallel societies in Stone Age Central Europe. Science 2013;342:479-481.

- 38 Barbujani G, Sokal RR, Oden NL: Indo-European origins: a computer-simulation test of five hypotheses. Am J Phys Anthropol 1995; 96:109-132.

- 39 Rendine S, Piazza A, Cavalli-Sforza L: Simulation and separation by principal components of multiple demic expansions in Europe. Am Nat 1986;128:681-706.

40 Currat M, Excoffier L: The effect of the Neolithic expansion on European molecular diversity. Proc Biol Sci 2005;272:679-688.

-41 François O, Currat M, Ray N, Han E, Excoffier L, Novembre J: Principal component analysis under population genetic models of range expansion and admixture. Mol Biol Evol 2010;27:1257-1268.

42 Arenas M, François O, Currat M, Ray N, Excoffier L: Influence of admixture and paleolithic range contractions on current European diversity gradients. Mol Biol Evol 2013;30: 57-61.

43 Currat M, Ray N, Excoffier L: SPLATCHE: a program to simulate genetic diversity taking into account environmental heterogeneity. Mol Ecol Notes 2004;4:139-142.
44 Edmonds CA, Lillie AS, Cavalli-Sforza LL: Mutations arising in the wave front of an expanding population. Proc Natl Acad Sci USA. 2004;101:975-979.

45 Klopfstein S, Currat M, Excoffier L: The fate of mutations surfing on the wave of a range expansion. Mol Biol Evol 2006;23:482-490.

46 Ray N, Currat M, Foll M, Excoffier L: SPLATCHE2: a spatially explicit simulation framework for complex demography, genetic admixture and recombination. Bioinformatics 2010;26:2993-2994.

47 Arenas M, Ray N, Currat M, Excoffier L: Consequences of range contractions and range shifts on molecular diversity. Mol Biol Evol 2012;29:207-218

48 Bramanti B, Thomas MG, Haak W, Unterlaender M, Jores $\mathrm{P}$, Tambets $\mathrm{K}$, AntanaitisJacobs I, Haidle MN, Jankauskas R, Kind CJ, Lueth F, Terberger T, Hiller J, Matsumura S, Forster P, Burger J: Genetic discontinuity between local hunter-gatherers and central Europe's first farmers. Science 2009;326:137-140.

49 Sanchez-Quinto F, Schroeder H, Ramirez O, Avila-Arcos MC, Pybus M, Olalde I, Velazquez AM, Marcos ME, Encinas JM, Bertranpetit J, Orlando L, Gilbert MT, LaluezaFox C: Genomic affinities of two 7,000-yearold Iberian hunter-gatherers. Curr Biol 2012; 22:1494-1499.

50 Haak W, Forster P, Bramanti B, Matsumura S, Brandt G, Tanzer M, Villems R, Renfrew C, Gronenborn D, Alt KW, Burger J: Ancient DNA from the first European farmers in 7500-year-old Neolithic sites. Science 2005; 310:1016-1018

51 Deguilloux MF, Soler L, Pemonge MH, Scarre C, Joussaume R, Laporte L: News from the west: ancient DNA from a French megalithic burial chamber. Am J Phys Anthropol 2011; 144:108-118.

52 Haak W, Balanovsky O, Sanchez JJ, Koshel S, Zaporozhchenko V, Adler CJ, Der Sarkissian CS, Brandt G, Schwarz C, Nicklisch N, Dresely V, Fritsch B, Balanovska E, Villems R, Meller H, Alt KW, Cooper A, Members of the Genographic Consortium: Ancient DNA from European early Neolithic farmers reveals their near eastern affinities. PLoS Biol 2010;8:e1000536

53 Sampietro ML, Lao O, Caramelli D, Lari M, Pou R, Marti M, Bertranpetit J, Lalueza-Fox C: Palaeogenetic evidence supports a dual model of Neolithic spreading into Europe. Proc Biol Sci 2007;274:2161-2167.

54 Behar DM, Harmant C, Manry J, van Oven M, Haak W, Martinez-Cruz B, Salaberria J, Oyharçabal B, Bauduer F, Comas D, Quintana-Murci L, Genographic Consortium: The Basque paradigm: genetic evidence of a maternal continuity in the Franco-Cantabrian region since pre-Neolithic times. Am J Hum Genet 2012;90:486-493.

55 Bollongino R, Burger J, Powell A, Mashkour M, Vigne JD, Thomas MG: Modern taurine cattle descended from small number of near-eastern founders. Mol Biol Evol 2012;29:2101-2104.
6 Malmstrom H, Gilbert MT, Thomas MG, Brandstrom M, Stora J, Molnar P, Andersen PK, Bendixen C, Holmlund G, Gotherstrom A, Willerslev E: Ancient DNA reveals lack of continuity between Neolithic hunter-gatherers and contemporary Scandinavians. Curr Biol 2009; 19:1758-1762.

57 Gamba C, Fernandez E, Tirado M, Deguilloux MF, Pemonge MH, Utrilla P, Edo M, Molist M, Rasteiro R, Chikhi L, Arroyo-Pardo E: Ancient DNA from an early Neolithic Iberian population supports a pioneer colonization by first farmers. Mol Ecol 2012;21:45-56.

58 Brandt G, Haak W, Adler CJ, Roth C, Szécsényi-Nagy A, Karimnia S, Möller-Rieker S, Meller H, Ganslmeier R, Friederich S, Dresely V, Nicklisch N, Pickrell JK, Sirocko F, Reich D, Cooper A, Alt KW, Genographic Consortium: Ancient DNA reveals key stages in the formation of central European mitochondrial genetic diversity. Science 2013;342:257-261.

59 Anderson CN, Ramakrishnan U, Chan YL, Hadly EA: Serial SimCoal: a population genetics model for data from multiple populations and points in time. Bioinformatics 2005; 21:1733-1734.

60 Der Sarkissian C, Balanovsky O, Brandt G, Khartanovich V, Buzhilova A, Koshel S, Zaporozhchenko V, Gronenborn D, Moiseyev V, Kolpakov E, Shumkin V, Alt KW, Balanovska E, Cooper A, Haak W, Genographic Consortium: Ancient DNA reveals prehistoric gene-flow from Siberia in the complex human population history of North East Europe. PLoS Genet 2013;9:e1003296.

61 Calafell F, Bertranpetit J: The genetic history of the Iberian Peninsula: a simulation. Curr Anthropol 1993;34:735-745.

62 Fix AG: Gene frequency clines in Europe: demic diffusion or natural selection? J R Anthropol Inst 1996;2:625-643.

63 Fix AG: Gene frequency clines produced by kin-structured founder effects. Hum Biol 1997;69:663-673.

64 Sjödin P, François O: Wave-of-advance models of the diffusion of the $\mathrm{Y}$ chromosome haplogroup R1b1b2 in Europe. PLoS One 2011; 6:e21592.

65 Aoki K: Modelling the spread of early farming and of the early Upper Palolithic in Europe; in Omoto K, Tobias PV (eds): The Origins and Past of Modern Humans - Towards Reconciliation. Kyoto, World Scientific, 1996, vol 3, pp 206-227.

66 Aoki K, Shida M, Shigesada N: Travelling wave solutions for the spread of farmers into a region occupied by hunter-gatherers. Theor Popul Biol 1996;50:1-17.

67 Currat M, Excoffier L, Maddison W, Otto SP, Ray N, Whitlock MC, Yeaman S: Comment on 'Ongoing adaptive evolution of ASPM, a brain size determinant in Homo sapiens' and 'Microcephalin, a gene regulating brain size, continues to evolve adaptively in humans'. Science 2006;313:172. 
68 Travis JM, Munkemuller T, Burton OJ, Best A, Dytham C, Johst K: Deleterious mutations can surf to high densities on the wave front of an expanding population. Mol Biol Evol 2007; 24:2334-2343.

69 Gerbault P, Moret C, Currat M, Sanchez-Mazas A: Impact of selection and demography on the diffusion of lactase persistence. PLoS One 2009;4:e6369.

70 Gerbault P, Liebert A, Itan Y, Powell A, Currat M, Burger J, Swallow DM, Thomas MG: Evolution of lactase persistence: an example of human niche construction. Philos Trans R Soc Lond B Biol Sci 2011;366:863-877.

71 Itan Y, Powell A, Beaumont MA, Burger J, Thomas MG: The origins of lactase persistence in Europe. PLoS Comput Biol 2009; 5:e1000491.
2 Currat M, Poloni ES, Sanchez-Mazas A: Human genetic differentiation across the Strait of Gibraltar. BMC Evol Biol 2010;10:237.

73 Riccio ME, Buhler S, Nunes JM, et al: 16(th) IHIW: analysis of HLA population data, with updated results for 1996 to 2012 workshop data (AHPD project report). Int J Immunogenet 2013;40:21-30.

74 Sanchez-Mazas A, Vidan-Jeras B, Nunes JM, et al: Strategies to work with HLA data in human populations for histocompatibility, clinical transplantation, epidemiology and population genetics: HLA-NET methodological recommendations. Int J Immunogenet 2012; 39:459-472; quiz 473-476.

75 Di D, Sanchez-Mazas A: Challenging views on the peopling history of East Asia: the story according to HLA markers. Am J Phys Anthropol 2011;145:81-96.
76 Ray N, Excoffier L: A first step towards inferring Ievels of long-distance dispersal during past expansions. Mol Ecol Resour 2010;10: 902-914.

77 Ray N, Currat M, Excoffier L: Incorporating environmental heterogeneity in spatially-explicit simulations of human genetic diversity; in Matsumura S, Forster P, Renfrew C (eds): Simulations, Genetics and Human Prehistory (Symposium). Cambridge, McDonald Institute for Archaeological Research, 2008, pp 103-117.

78 Deguilloux MF, Mendisco F: Ancient DNA: a window to the past of Europe. Hum Hered 2013;76:121-132.

79 Petit RJ, Excoffier L: Gene flow and species delimitation. Trends Ecol Evol 2009;24:386393. 